\title{
ПРИМЕНЕНИЕ ОБРАЩЕННОИ ГАЗОВОЙ ХРОМАТОГРАФИИ В ИССЛЕДОВАНИИ ТЯЖЕЛОЙ СМОЛЫ СЛАНЦА-КУКЕРСИТА
}

\author{
(Представил О. Эйзен)
}

Возможности газовой хроматографии не ограничиваются только аналитическими областями применения, они позволяют также решить целый ряд неаналитических проблем. Например, методом обращенной газовой хроматографии (ОГХ) можно исследовать термодинамические свойства вещества неподвижной фазы, в качестве которой могут служить самые различные соединения и их смеси $\left[{ }^{1,2}\right]$. При этом большое преимущество метода ОГХ перед калориметрией в области предельного разбавления состоит в относительно простом выполнении эксперимента и надежности полученной информации.

Если аналитические аспекты газовой хроматографии нашли самое широкое применение в химии топлив, то этого нельзя сказать о методе ОГХ. Первые шаги в этой области были сделаны в работах [3-5], где использовали метод ОГХ для исследования жидких топлив - нефтяных остатков. Позднее метод ОГХ был применен в исследовании битума ромашкинской нефти [ $\left.{ }^{6}\right]$. Отмеченное в вышеперечисленных работах взаимодействие между молекулами известного соединения (сорбата) и неподвижной фазы характеризуется относительным удерживаемым объемом сорбата. В качестве стандарта здесь принимается гипотетический алкан, имеющий молекулярную массу, равную массе сорбата.

Нетрудно заметить, что такая трактовка результатов хроматографического экоперимента термодинамически необоснована и поэтому не может отобразить сущность межмолекулярных процессов в неподвижной фазе. Однако знание такой информации оказывает существенную помощь в интерпретации результатов, полученных другими методами, или же позволяет обоснованно планировать направления дальнейшего экспериментирования. В настоящей работе на примере смолы сланца-кукерсита показана возможность исследования свойств сложных жидких топлив методом ОГХ.

\section{Теоретические основы}

Согласно теоретическим предпосылкам газовой хроматографии связь между абсолютным удерживаемым объемом $\left(V_{g}^{0}\right)$ и коэффициентом активности $\left(\gamma^{\infty}\right)$ сорбата в неподвижной фазе передается формулой

$$
V_{g}^{0}=\frac{273,2 \cdot R}{M \cdot \gamma^{\infty} \cdot P^{0}}
$$

где $M$ - молекулярная масса жидкой фазы и $P^{0}$ - давление паров чистого сорбата при данной температуре колонки, Для различных 
неподвижных фаз в случае одного и того же сорбата при постоянстве температуры справедливо соотношение

$$
\frac{V_{g(0)}^{0}}{V_{g(1)}^{0}}=\frac{\gamma_{(1)}^{\infty} \cdot M_{(1)}}{\gamma_{(0)} \cdot M_{(0)}} .
$$

Приведенные в скобках индексы характеризуют принадлежность данной величины той или иной неподвижной фазе. Дифференцируя логарифмический вид уравнения (1) по обратной величине абсолютной температуры, получим

$$
R \frac{d \ln V_{g}^{0}}{d\left(\frac{1}{T}\right)}=\Delta H_{S}=\Delta H_{V}-\Delta H_{M}^{E},
$$

где $\Delta H_{S}$ - энтальпия растворения сорбата в жидкой фазе; $\Delta H_{V}-$ энтальпия испарения сорбата; $\Delta H_{M}^{E}-$ избыточная энталыпия смешения сорбата.

Термодинамическая функция $\Delta H_{M}^{E}$ представляет собой разность между свойствами чистого сорбата (сорбат сам в себе) и его раствора. В условиях бесконечного разбавления сорбата в неподвижной фазе, когда взаимодействиями между молекулами сорбата можно пренебречь, величина и знак $\Delta H_{M}^{E}$ отражают характер взаимодействия между молекулами сорбата и неподвижной фазы. Отрицательный знак при $\Delta H_{M}^{E}$ свидетельствует о наличии сильного взаимодействия между компонентами раствора, а положительный - слабого.

Из термодинамики хорошо известно, что

$$
R T \ln \gamma^{\infty}=\Delta G_{M}^{E}=\Delta H_{M}^{E}-T \Delta S_{M}^{E},
$$

где $\Delta G_{M}^{E}-$ избыточная свободная энергия смешения, $\Delta S_{M}^{E}-$ избыточная энтропия омешения.

\section{Экспериментальная часть}

В экспериментальной работе пользовались усовершенствованным газовым хроматографом «Вилли-Гиде». Для повышения точности термостатирования в хроматограф была вмонтирована спираль из медной трубки, через которую прокачивали воду из ультратермостата. Колонки из нержавеющей стали размерами $1,0 \times 0,004$ м были заполнены твердым носителем «Инертоном AW» 0,25-0,315 мм, пропитанным тяжелой смолой, $30 \%$ от веса носителя. Количество неподвижной фазы в колонке определяли с точностью до $10^{-6}$ ке. Колонку взвешивали до и после опыта. Температуру в термостате измеряли с точностью 0,1 град. Скорость газа-носителя (гелий) на выходе из колонки измеряли с помощью мыльно-пленочного ротаметра.

Тяжелая сланцевая смола - остаток дистилляции генераторной смолы с началом кипения $573 \mathrm{~K}$ (398 K при 267 Па), плотностью при $293 \mathrm{~K} 1037 \kappa 2 / \mu^{3}$ и средней молекулярной массой 340. Содержание карбонильной группы равно $0,36 \cdot 10^{-3} \kappa 2-э \kappa в / \kappa 2$. Групповой состав смолы, \%: углеводороды-22, нейтральные кислородные соединения 49 , фенолы - 28 и прочие - 1. В качестве сорбатов использовались органические растворители марок ч., ч.д. а. без дополнительной очистки. 
С целью окисления сланцевой смолы через колонки пропускали воздух из баллона при $323 \mathrm{~K}$ со скоростью $(0,8-1,0) \cdot 10^{-6} \mathrm{M}^{3} / c$. После каждого сеанса окисления, перед измерением времен удерживания сорбатов колонку кондиционировали продуванием гелия в течение свыше 6 и.

\section{Результаты и обсуждение}

На основании экспериментальных данных были рассчитаны $V_{g}^{0} 17$ opганических соединений в тяжелой сланцевой смоле при различных температурах в интервале 309-344 К. Из рис. 1 следует, что зависимость $\ln V_{\mathrm{g}}^{0}$ от величины $1 / T$ хорошо описывается уравнением прямой

$$
\ln V_{g}^{0}=a+\frac{b}{T} .
$$

Таким образом, результаты измерений, проведенных с применением трех разных колонок, сходные. Рассчитанные с помощью (3) значения $\Delta H_{\mathrm{S}}$ и $\Delta H_{M}^{E}$ приведены в табл. 2. Необходимые значения энтальпии испарения органических соединений при температуре $298 \mathrm{~K}$ рассчитаны с применением данных, заимствованных из [7]. При этом изменениями в составе неподвижной фазы пренебрегали, т. к. суммарный вынос жидкой фазы из колонки не превышал $0,5 \%$. При определении величины $\gamma^{\infty}$, состояние газовой фазы принято идеальным, т. к. поправка на неидеальность в случае применения гелия ничтожна. Для экстраполяции значений $V_{g}^{0}$ до $298 \mathrm{~K}$ использовали коэффициенты $a$ и $b$ (табл. 1). Отсутствие значимой корреляции между величинами $V_{\mathrm{g}}^{0}$ и термодинамическими функциями смешения $\left(\Delta G_{M}^{E}, \Delta H_{M}^{E}\right.$ и $\left.\Delta S_{M}^{E}\right)$ и наличие существенной корреляции между $\Delta S_{M}^{E}$ и $\Delta H_{M}^{E}$ (табл. 3) служат дополнительными доказательствами содержательности и надежности полученной информации.

Из анализа характеристик смешения, приведенных в табл. 2, выте-

Таблица 1

Коэффициенты (5) и абсолютные удерживаемые объемы органических соединений в тяжелой сланцевой смоле при $298 \mathrm{~K}$

\begin{tabular}{|c|c|c|c|c|c|c|}
\hline \multirow{2}{*}{$\begin{array}{l}\text { के } \\
\text { ¿̇ } \\
\text { I. }\end{array}$} & \multirow{2}{*}{ Соединения } & \multicolumn{2}{|c|}{ Коэффициент (5) } & \multirow{2}{*}{$\begin{array}{c}\text { Коэффи- } \\
\text { циент } \\
\text { корре- } \\
\text { ляции }\end{array}$} & \multirow{2}{*}{$\begin{array}{l}\text { Число } \\
\text { точек }\end{array}$} & \multirow{2}{*}{$\begin{array}{c}V^{0}, \\
g \\
M^{3} / \kappa 2\end{array}$} \\
\hline & & $a$ & $b$ & & & \\
\hline 1. & Гексан & $-4,37$ & 2590 & 0,982 & 20 & 0,075 \\
\hline 2. & Гептан & $-6,00$ & 3480 & 0,995 & 16 & 0,290 \\
\hline 3. & Октан & $-6,97$ & 4140 & 0,999 & 7 & 1,006 \\
\hline 4. & 1-Гексен & $-4,53$ & 2660 & 0,993 & 12 & 0,081 \\
\hline 5. & 1-Гептен & $-6,22$ & 3580 & 0,998 & 10 & 0,315 \\
\hline 6. & 1-Октен & $-7,84$ & 4450 & 0,994 & 7 & 1,191 \\
\hline 7. & Циклогексан & $-3,67$ & 2620 & 0,983 & 13 & 0,167 \\
\hline 8. & Бензол & $-5,03$ & 3290 & 0,994 & 16 & 0,405 \\
\hline 9. & Толуол & $-7,00$ & 4300 & 0,999 & 6 & 1,614 \\
\hline 10. & Метилен хлористый & $-4,45$ & 2690 & 0,993 & 15 & 0,097 \\
\hline 11. & Хлороформ & $-5,20$ & 3200 & 0,994 & 17 & 0,252 \\
\hline 12. & Четыреххлористый углерод & $-3,97$ & 2840 & 0,995 & 12 & 0,258 \\
\hline 13. & Метиловый спирт & $-8,62$ & 4200 & 0,990 & 31 & 0,236 \\
\hline $\begin{array}{l}14 . \\
15\end{array}$ & $\begin{array}{l}\text { Этиловый спирт } \\
\text { Аџетон }\end{array}$ & $\begin{array}{r}-9,58 \\
-8,53\end{array}$ & 4770 & 0,997 & 8 & 0,612 \\
\hline 16. & $\begin{array}{l}\text { Ацетон } \\
\text { Диэтиловый эфир }\end{array}$ & $\begin{array}{l}-8,53 \\
-7,53\end{array}$ & $\begin{array}{l}4460 \\
3780\end{array}$ & $\begin{array}{l}0,996 \\
0990\end{array}$ & 20 & 0,618 \\
\hline 17. & Этилацетат & $-10,30$ & 5220 & 0,995 & 7 & 1,346 \\
\hline
\end{tabular}




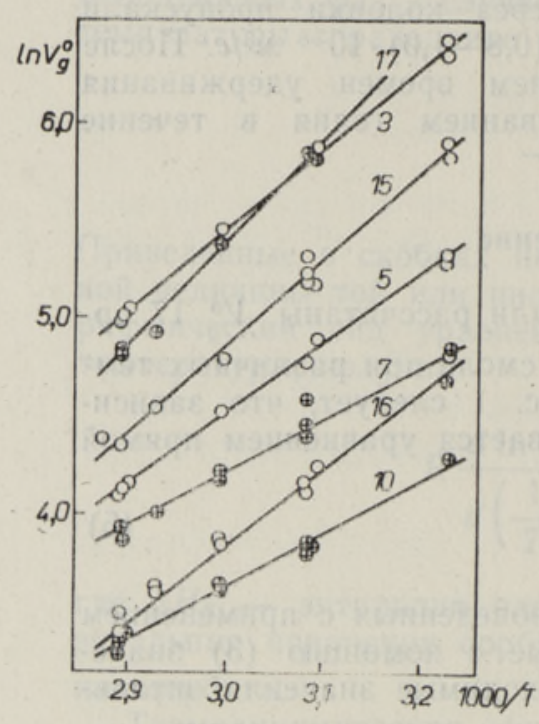

Рис. 1. Температурная зависимость абсолютных удерживаемых объемов органических соединений в тяжелой сланцевой смоле. Обозначения соединений соответствуют приведенным в табл. 1.

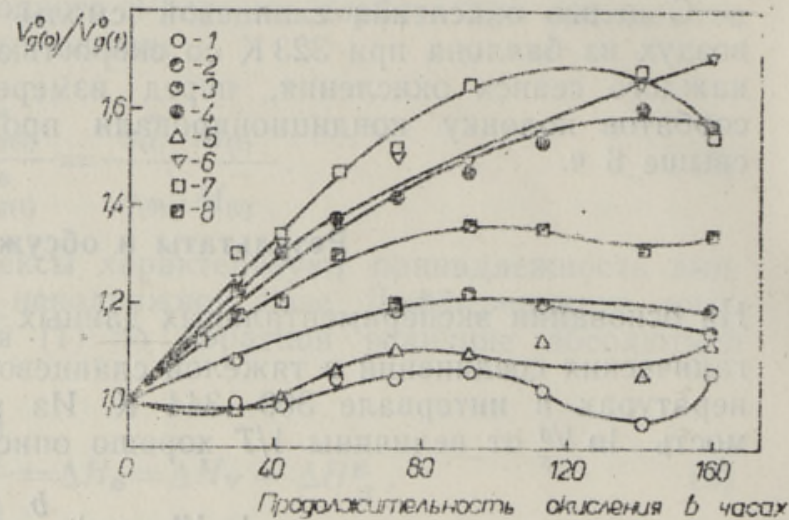

Рис. 2. Зависимость величины отношения $V_{g(0)}^{0} / V_{g(t)}^{0}$ органических соединений от продолжительности окисления тяжелой сланцевой смолы кислородом воздуха при 323 К. 1 - хлороформ, 2 - 1-гептен, 3 - гептан, 4 - этилацетат, 5 - бензол, 6 - ацетон, 7 - диэтиловый эфир, 8 - метиловый спирт. ${ }_{g(0)}^{V^{0}}$ и $_{g(t)}^{0}$ принадлежат, соответственно, исходной и обработанной смоле.

кает, что кислородсодержащие растворители с протоноакцепторными свойствами (ацетон, диэтиловый эфир и этилацетат) хорошо растворяются и растворяют сланцевую смолу. Их коэффициенты активности ниже единицы, а избыточные энтальпии смешения имеют отрицательные знаки, что указывает на образование комплексов между молекулами сорбата и неподвижной фазой за счет Н-связи. Относительно низкие значения $\gamma^{\infty}$ и положительные значения величины $\Delta H_{M}^{E}$ для спиртов свидетельствуют, очевидно, о том, что исследованная смола по своей способности образовывать Н-связи уступает низшим спиртам. Эти выводы отлично согласуются с данными практических наблюдений.

Окисление сланцевой смолы кислородом воздуха в мягких условиях, при температуре $323 \mathrm{~K}$, вызвало заметные изменения ее свойств. Из рис. 2 следует, что в результате окисления омолы значения $V_{g}^{0}$ у всех использованных сорбатов, как правило, уменьшались. Указанный факт можно объяснить изменениями как значений $\gamma^{\infty}$ сорбатов, так и молекулярной массы смолы (2). Молекулярная масса смолы, смытой с твердого носителя после 160-часового окисления, составляла 450, т. е. увеличилась за это время в 1,3 раза. Такое уменьшение измеряемых значений $V_{g(t)}^{0}$ метанола по отношению к начальному $V_{g(0)}^{0}$ практически дает право объяснить данный факт только изменениями самой молекулярной массы смолы. Для других рассматриваемых соединений придется учесть еще изменения значений их $\gamma^{\infty}$.

Согласно вышесказанному, значения $\gamma^{\infty}$ для гептана, 1-гептена, бензола и хлороформа в окисленной смоле более низкие, чем в исходной смоле, а значения $\gamma^{\infty}$ для ацетона, диэтилового эфира и этилацетата - бо́льшие. Если для гептана и 1-гептена незначительные изменения в значениях $\gamma^{\infty}$ можно объяснить лишь энтропийным эффектом 
Энтальпия растворения, избыточные термодинамические функции смешения и коэффициенты активности органических соединений при бесконечном разбавлении в тяжелой сланцевой смоле при $298 \mathrm{~K}$

\begin{tabular}{|c|c|c|c|c|c|}
\hline \multirow[t]{2}{*}{ Соединения } & $\Delta H_{S}$ & $\Delta G_{M}^{E}$ & $\begin{array}{r}\Delta H_{M}^{E} \\
\text { E }\end{array}$ & \multirow{2}{*}{$\begin{array}{c}\Delta S_{M}^{E}, \\
\text { Дж/K·моль }\end{array}$} & \multirow{2}{*}{$\gamma^{\infty}$} \\
\hline & \multicolumn{3}{|c|}{$\kappa Д ж / м о л ь$} & & \\
\hline Гексан & 21,5 & 3,68 & 10,50 & 22,8 & 4,42 \\
\hline Гептан & 29,0 & 3,29 & 7,95 & 15,6 & 3,77 \\
\hline Октан & 34,4 & 3,15 & 7,53 & 14,7 & 3,57 \\
\hline 1-Гексен & 22,1 & 2,99 & 9,08 & 20,4 & 3,34 \\
\hline 1-Гептен & 29,7 . & 2,57 & 6,19 & 12,1 & 2,82 \\
\hline 1-Октен & 37,0 & 2,18 & 3,68 & 5,0 & 2,41 \\
\hline Циклогексан & 21,8 & 2,79 & 11,55 & 29,4 & 3,08 \\
\hline Бензол & 27,4 & 0,65 & 6,78 & 20,5 & 1,30 \\
\hline Толуол & 35,7 & 0,21 & 2,64 & 8,12 & 1,09 \\
\hline Метилен хлористый & 22,3 & 0,47 & 6,90 & 21,5 & 1,21 \\
\hline Хлороформ & 26,7 & 0,05 & 5,73 & 19,0 & 1,02 \\
\hline Четыреххлористый углерод & 23,6 & 1,31 & 9,04 & 25,9 & 1,70 \\
\hline Метиловый спирт & 34,9 & 1,31 & 3,93 & 8,8 & 1,70 \\
\hline Этиловый спирт & 39,7 & 0,83 & 2,76 & 6,4 & 1,40 \\
\hline Ацетон & 37,1 & $-2,60$ & $-5,31$ & $-9,1$ & - 0,35 \\
\hline Диэтиловый эфир & 31,5 & $-1,57$ & $-3,14$ & $-5,2$ & 0,53 \\
\hline Этилацетат & 43,4 & $-2,33$ & $-7,49$ & $-17,3$ & 0,39 \\
\hline
\end{tabular}

таблица 3

Корреляционная матрица характеристик смешения органических соединений в тяжелой сланцевой смоле

\begin{tabular}{c|r|r|r|r|r}
\hline & $V_{g}^{0}$ & $\Delta H_{S}$ & $\Delta G_{M}^{E}$ & $\Delta H_{M}^{E}$ & \multicolumn{1}{c}{$\Delta S_{M}^{E}$} \\
\hline$V_{g}^{0}$ & \multirow{2}{*}{1,000} & 0,765 & $-0,296$ & $-0,490$ & $-0,543$ \\
$\Delta H_{S}$ & & 1,000 & $-0,516$ & $-0,785$ & $-0,851$ \\
$\Delta_{M}^{E}$ & & & 1,000 & 0,879 & 0,737 \\
$\Delta_{M}^{E} H_{M}^{E}$ & & & & 1,000 & 0,970 \\
$\Delta_{M}^{E}$ & & & & & 1,000
\end{tabular}

$\left(\Delta S_{M}^{E}\right.$ растет из-за увеличения разницы в молекулярных объемах сорбата и смолы), то для бензола, хлороформа и кислородсодержащих соединений приходится учитывать также изменение характера межмолекулярного взаимодействия (изменяется $\Delta H_{M}^{E}$ ).

Поскольку изменения в $\Delta H_{M}^{E}$ наибольшие для ацетона, диэтилового эфира и этилацетата, то это непосредственно указывает на то, что в смоле после ее окисления увеличивается содержание группировок с протоноакцепторными свойствами (карбонильные и эфирные). Правомерность такого вывода подтверждают результаты работ [8] и [ ${ }^{9}$, а также анализ окисленной смолы. В последней после проведения

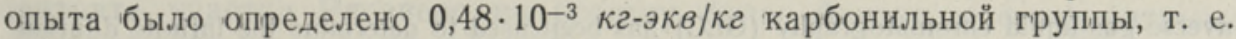
в 1,3 раза больше, чем в исходной смоле.

Из вышесказанного следует, что характер экспериментальных кривых, изображенных на рис. 2, не случайный: он отражает конкретные изменения, наблюдавшиеся в системе сланцевая смола-органический 
растворитель. Экстремумы некоторых кривых, которые особенно заметны в случае применения бензола и хлороформа, очевидно, отвечают определенным изменениям свойств сланцевой смолы при ее окислении. Выяснение сущности этих процессов, однако, требует дальнейших исследований другими методами. Автор выражает благодарность Н. Винк и Э. Грюнер за определение молекулярных масс и химический анализ.

\section{ЛИТЕРАТ У Р А}

1. Король А. Н. Определенне термодинамических функций растворов при помощи газо-жидкостной хроматографин. - Успехи химии, 1972, т. 41, вып. 2, c. $321-345$.

2. Нестеров А. Е., Л и патов Ю. С. Обращенная газовая хроматография в термодинамике полимеров. Киев, 1976.

3. D a vis, T. C., Peterse n, J. C., H a in es, W. E. Inverse gas-liquid chromatography. A new approach for studying petroleum asphalts. - Anal. Chem., 1966, v. 38, N 2, p. $241-243$.

4. Davis, T. C., Petersen, J. C. An adaption of inverse gas-liquid chromatography to asphalt oxidation studies. - Anal. Chem., 1966, v. 38, N 13, p. $1938-1940$.

5. B a rbour, F. A., D orrence, S. M., Petersen, J. C. Inverse gas-liquid chromatographic studies of asphalt. - Anal. Chem., 1970, v. 42, N 6, p. 668670 .

6. Boduszynski, M., Szkuta-Pochopien, T. Investigations on Romashkino asphaltic bitumen. 2. Study of maltenes fractions using inverse gas-liquid chromatography. - Fuel, 1977, v. 56, p. 149-152.

7. Langes Handbook of Chemistry. New York, 1979.

8. Л и й в Э.'Х. Химизм процесса образования сланцевого окисленного битума. В кн.: Сланцевый битум. Таллин, 1959, с. $232-246$.

9. Кундель Х. А., Халевина Т. А., Передкова Н. М. Изменение группового состава генераторной смолы в результате ее нагрева в окислительной атмосфере. - Горючие сланцы, 1981, вып. 8, с. 12-15.

Ннститут химии

Академии наук Эстонской ССР

Поступила в редакцию 9/XII 1981

J. ARRO

\section{POOORATUD GAASIKROMATOGRAAFIA KASUTAMINE KUKERSIIDI RASKEOLI UURIMISEL}

Pööratud gaasikromatograafia meetodil on määratud kukersiidi raskeôlis 17 órgaanilise ühendi (alkaanid, alkeenid, aromaatsed süsivesinikud, alkoholid, atsetoon, dietüüleeter ja etüületanaat) aktiivsustegurid ja termodünaamilised liigsegunemisfunktsioonid temperatuuril $298 \mathrm{~K}$. Leiti, et pōlevkiviôli õhuhapnikuga oksüdeerimine gaasikromatograafi kolonnis põhjustab orgaaniliste ühendite väljumismahtude vähenemist (võrreldes esialgse õliga). Saadud tulemusi on interpreteeritud.

\section{J. ARRO}

\section{THE USE OF INVERSE GAS-LIQUID CHROMATOGRAPHY IN INVESTIGATING HEAVY KUKERSITE SHALE OIL}

Inverse gas-liquid chromatography (GLC) has been used to determine the infinite dilution activity coefficients and excess thermodynamic functions of mixing for 17 organic compounds (alkanes, alkenes, aromatic hydrocarbons, alcohols, acetone, ethyl ether and ethyl acetate) in heavy kukersite shale oil at $298 \mathrm{~K}$. After the oxidation of shale oil in GLC column with air oxygen the retention volumes of organic compounds are smaller than in the case of untreated shale oil. The results have been discussed. 